\title{
THE BARROW 21 OF THE BURIAL GROUND FILIPPOVKA I: ITEMS OF HORSE EQUIPMENT AND DATE OF THE COMPLEX
}

\author{
(C) 2018
}

Myshkin Vladimir Nikolaevich, candidate of historical sciences, head of Archaeological Laboratory Samara State University of Social Sciences and Education (Samara, Russian Federation)

\begin{abstract}
This article deals with equestrian ammunition items found near the burial mound of the 21 Filipovka I burial ground in the Orenburg region in order to establish the time of construction of this burial mound. The burial mound Filippovka I was a necropolis of the social elite of nomads who inhabited the steppes of the Southern Urals in the middle of the 1st millennium BC. The richness of the funerary inventory and the complexity of the ritual actions performed during the erection of the burial mounds make it possible to study many aspects of the history and culture of these tribes. This determines the importance of a comprehensive study of the materials of this burial ground. Equipping a horse includes four bronze objects: two bridle plaques, check-piece and headband decoration bridle were found around the barrow 21 Filippovka I burial ground. Some of these items have close analogies among the details of equine ammunition from the Scythian monuments of the Black Sea North Littoral, dated by import items. The analogies that exist among the Scythian antiquities allow us to date the burial mound of the burial ground of Filippovka I during the time of the 4th century BC. The presence of such things as a headband in the form of a griffin head and a bridle plaque in the form of a wolf's head fixes the existence of the cultural interaction of nomads who left the burial ground of Filippovka I with the western Scythian world of the Northern Black Sea Coast.

Keywords: Early Iron Age; steppes; Southern Urals; Ural river basin; nomadic cattle-breeding tribes; cemetery; burial mound; barrow grave; social elite; horsemen; horse equipment; sacrificial complex; bridle; check-piece; bridle plaques; headband decoration; chronology; date; ethnocultural ties.
\end{abstract}

\section{СОЦИАЛЬНАЯ ЗАЩИТА РАБОТНИЦ ПРОМЫШЛЕННЫХ ПРЕДПРИЯТИЙ САНКТ-ПЕТЕРБУРГА ВО ВТОРОЙ ПОЛОВИНЕ ХІХ - НАЧАЛЕ ХХ В. КАК ОДИН ИЗ АСПЕКТОВ ЖЕНСКОЙ ИСТОРИИ ПОВСЕДНЕВНОСТИ}

(C) 2018

\author{
Северцева Ольга Валентиновна, преподаватель истории \\ Выборгский институт (филиал) Ленинградского государственного университета им. А.С. Пушкина \\ (2. Выборг, Ленинградская область, Российская Федераиия)
}

Аннотащия. В статье говорится о мерах социальной защиты работниц промышленных предприятий Санкт-Петербурга во второй половине XIX - начале XX в. Социальная защищенность является важной частью повседневной жизни любого человека, особенно женщин. Именно на их плечах лежит большая часть забот о семье и детях. Но законы, принимаемые в Российской империи в рамках фабричного законодательства, были направлены скорее на поддержку интересов промышленных предпринимателей, чем их работниц. Законодательные акты, которые должны были гарантировать женщинам-работницам социальную защиту, практически не соблюдались. Многие из этих законов даже были отменены более поздними нормативноправовыми актами. Работницы так и не получили равную с мужчинами оплату труда. Продолжительность рабочего дня предприниматели также могли устанавливать практически по своему усмотрению, удлиняя его сверхурочными работами. Отпуск по беременности и по уходу за новорожденным, был гарантирован работницам только с 1912 г. Выплата пособий при получении травмы на производстве фактически зависела от желания и порядочности работодателя. Фабричная инспекция не являлась помощником в деле урегулирования взаимоотношений между работницами и хозяевами предприятий. Но самое главное, работницы фабрик и заводов Санкт-Петербурга во второй половине XIX - начале XX в. не получили реальной возможности на защиту своих интересов и прав, не нарушая законодательство.

Ключевые слова: повседневность; работницы; промышленные предприятия; Санкт-Петербург; социальная защита; фабричное законодательство; продолжительность рабочего дня; оплата труда; штрафы; сверхурочная работа; травмы на производстве; отпуск по беременности и уходу за ребенком; женская фабричная инспекция; защита прав.

Повседневная жизнь женщин становится одной из актуальнейших тем в современных исследованиях истории повседневности. «Обращение к изучению повседневной жизни представительниц различных профессиональных групп в те или иные периоды российской истории помогает выделить как профессиональные, так и гендерные факторы в социальном положении людей, занятых в определенной сфере деятельности» [1, с. 10].

Женщины, трудящиеся на промышленных предприятиях Санкт-Петербурга, как и всей России, во второй половине XIX - начале XX в. являлись одной из самых незащищенных категорий работников. Они получали меньшую заработную плату по сравнению с мужчинами [2, с. 99]. Продолжительность рабочего дня фактически была одинаковой для мужчин и женщин. Трудились и в выходные, и в праздничные дни, оставались и на сверхурочную работу [3, с. 77 ; 4, с. 29]. Женщинам приходилось работать на предприятии практически до последнего дня беременности, а иногда роды происходили прямо в мастерских [4, с. 42]. До 1912 г. они не имели законного отпуска по беременности и по уходу за новорожденным. Длительное нахождение в антисанитарных мастер- 
ских губительно действовало на здоровье работниц [5, с. 46; 4, с. 40; 6, с. 67]. Женщины подвергались постоянным унижениям, оскорблениям, побоям и сексуальным домогательствам не только со стороны администрации предприятий, но и мужчин-рабочих, с которыми им приходилось трудиться каждый день [5, с. 43-44; 7, л. 1-2; 8, л. 5-6; 9, л. 20].

Изменить условия труда женщин на промышленных предприятиях в дореволюционный период должны были следующие меры:

- разработка и принятие эффективных законодательных актов;

- создание систем контроля над исполнением законов и справедливого наказания за их нарушение;

- налаживание гибких методов «обратной» связи со всеми субъектами экономических отношений в промышленности.

В самодержавной России без изменения существовавшего политического строя выполнение всех этапов построения тесного взаимодействия между властью, промышленниками и непосредственно пролетариатом была невозможной. Соответственно и меры, принимаемые для социальной поддержки работниц промышленной сферы, были малоэффективны. Рассмотрим более детально каждый из пунктов.

«...Уже к концу 1850-х годов в правительственных кругах среди наиболее либеральных их представителей зрело понимание того, что с освобождением крестьян уже нельзя сохранять прежние законы о рабочих, что необходимость разработки фабричнозаводского законодательства очевидна» [10]. Выдвигались различные законопроекты, работали комиссии по исследованию условий труда и быта рабочих фабрично-заводской сферы. Но только массовые забастовки рабочих в 1870-х годах дали толчок к срочному принятию решительных мер по государственному урегулированию взаимоотношений между рабочими и предпринимателями. В 1882 г. либеральный журнал «Отечественные записки» писал: «Мы, несомненно, накануне введения в России фабричного законодательства... Чувствовалась потребность не в частных мерах, которые к тому же не имеют силы и значения общегосударственного закона и просто игнорируются, а в создании общего фабричного законодательства, которое было бы одинаково обязательно для всех концов России... [11, с. 1].

Многие исследователи дореволюционного, советского и современного периодов в своих работах освещали основные положения фабричного законодательства Российской империи. Они пришли к ряду основных выводов:

- фабричное законодательство не являлось системой, законы принимались хаотично, проходил длительный период времени между принятием одного и другого законодательного акта;

- принятие каждого законодательного документа происходило под давлением со стороны предпринимателей и забастовок рабочих;

- законы носили локальный характер, не охватывали все категории промышленных рабочих;

- законы были направлены скорее на поддержку хозяев фабрик и заводов, чем на меры социальной защиты рабочих $[2 ; 4 ; 10 ; 12 ; 13 ; 14 ; 15$, с. 164; 16].

Результатом этих законодательных инициатив стало то, что фабричным законодательством были недовольны и хозяева предприятий, и наемные рабочие, и сами законодатели. Некоторые исследователи говорили о российском законодательстве как о «самом отсталом фабричном законодательстве Европы» $[16$, c. $115 ; 14$, с. $22-23]$.

Остановимся на некоторых законах, которые должны были выстроиться во взаимосвязанную систему государственной поддержки и защиты женщин-работниц промышленных предприятий. «В 1860-е - середине 1880-х годов социальное положение рабочих по сравнению с дореформенным ухудшилось. Снижение реальной заработной платы, повсеместная практика бесконтрольного взимания штрафов, усиление напряженности труда провоцировали рост недовольства. Всплеск стачечного движения 1884-1885 годов стимулировал выработку правительственных мер по разрешению наиболее болезненных социальных проблем рабочих» [17, с. 51].

3 июня 1885 г. был принят закон «О воспрещении ночной работы несовершеннолетним и женщинам на фабриках, заводах и мануфактурах» [18]. Закон был принят по просьбе петербургских фабрикантов, так как в это время наблюдалось перенасыщение рынка производимыми товарами, что могло привести к полному закрытию фабрик и увольнению сотрудников $[10 ; 12$, с. $29-32 ; 13$, с. 30-45].

Петербургские предприниматели, ратуя за принятие этого закона, даже приводили аргумент, что его реализация послужит нравственной чистоте женщинработниц, которые будут по ночам находиться дома со своей семьей. Один из петербургских фабричных инспекторов В.П. Литвинов-Фалинский считал данный повод совершенно несостоятельным. «...Едва ли можно подтвердить доказательно, что работа ночью в фабричном корпусе представляется в нравственном отношении худшею для рабочих, в сравнении с нахождением их в то же время в казармах или иных местах, как, например, в питейных или других подобных заведениях, существующих для разгула...» [13, с. 34]. Тем не менее законодатели, идя навстречу петербургским промышленникам, издали закон о запрещении работы несовершеннолетним и женщинам в ночное время.

Закон вызвал бурю негодования у московских предпринимателей. Но и они в скором времени смогли наладить работу на своих предприятиях без нарушений законодательства. «На крупнейших текстильных фабриках Центрального промышленного района вводилась двухсменная работа по 9 часов и сдельная оплата труда. Это позволяло обеспечивать большую интенсивность труда. Некоторые предприятия переходили на 13-14-часовую работу для женщин и подростков в дневные часы, что значительно ухудшало положение последних. Капиталисты настолько быстро и успешно приспособились к данному закону, что это дало основание министру финансов И.А. Вышнеградскому в октябре 1888 г. признать: «Действующие узаконения о работе малолетних, подростков и женщин в настоящем виде не представляют существенных неудобств, и немедленное изменение их не вызывается настоятельной надобностью» [10]. Кроме того, в 1890 г. был принят новый правовой акт, в который вошли некоторые ранее изданные законы, в том числе и Закон от 3 июня 1885 г. В новом документе работа женщин в ночное 
время разрешалась в «случаях особо уважительных...», чем и стали повсеместно пользоваться хозяева предприятий [19, с. 49].

Так как принятие этого закона нисколько не снизило градус напряжения во взаимоотношениях между предпринимателями и рабочими, а забастовки продолжались, то законодателям пришлось предпринимать более решительные шаги в урегулирование производственных отношений.

Уже 3 июня 1886 г. были приняты «Правила о надзоре за заведениями фабричной промышленности и взаимных отношениях фабрикантов и рабочих» [20]. Этот постановление стало «основным правовым актом трудового законодательства в царской России» $[5$, c. 20].

Правила должны были урегулировать общий порядок приема и увольнения рабочих, своевременность оплаты труда, штрафы, сверхурочные работы и т.д., то есть практически все взаимоотношения между рабочими и предпринимателями. Для женщин, нанимаемых для работы на фабрику, причем только замужних, в этих правилах был прописан лишь один пункт. «При найме замужних женщин... имеющих отдельный вид на жительство, не требуется особого позволения родителей, опекунов или мужей» [20, c. 263]. Это разрешение, казалось бы, должно было расширить свободу выбора женщин. Но дело в том, что получить паспорт замужней женщине без разрешения мужа было крайне затруднительно [21, с. 244 $245 ; 22]$. Все остальные пункты Закона от 1886 г. под определением «рабочий» подразумевали и мужчин, и женщин.

Многие параграфы изданных правил, действительно, должны были улучшить положение рабочих фабрично-заводской промышленности. Например:

- при найме на предприятие в течение семи дней должна была выдаваться расчетная книжка, что позволяло рабочим контролировать правильную запись проделанной ими работы [20, с. 263];

- запрещалось понижать заработную плату до окончания договора о найме или предупредив об этом за две недели, что позволяло рабочему уволиться, если он не желал трудиться за меньшие деньги [20, с. 263];

- выдаваться заработная плата должна была один раз в месяц при найме на месяц или более и два раза в месяц, если работник был нанят на срок неопределенный [20, с. 263];

- получать заработную плату рабочие должны были только деньгами, ни товаром, ни купонами, ни какими иными предметами расплачиваться запрещалось [20, с. 263].

Но на некоторых предприятиях:

- деньги, заработанные рабочими, в расчетную книжку записывались, но не выплачивались [12, с. 49];

- товары, выданные рабочим вместо денег, записывались «выданными чистыми деньгами» [12, с. 49];

- вместо штрафа записывалось меньшее количество дней, которые отработал человек, либо штраф совсем не записывался [7, л. 1-2; 12, с. 49];

- штрафы не взимались, но понижались расценки и выдавались премии послушным рабочим [3, с. 7677];

- рабочие боялись пожаловаться, так как, мало того что их уволят с этого предприятия, не возьмут и ни на какое другое - предприниматели вели своеобразные «черные списки», обменивались с другими хозяевами заводов и фабрик данными о неблагонадежных работниках [4, с. 32-33; 49];

За нарушение этого Закона для рабочих следовало уголовное наказание, для хозяев - штраф. [14, c. $22 ; 12$, с. $47 ; 10]$. Рабочие не имели права обжаловать распоряжение администрации о наложении штрафа [2, с. 112].

Однако при всех недостатках и разночтениях Закон от 1886 г. во многом ограничивал права работодателей. Советский историк А.Н. Ацаркин писал: «Как ни ограничен закон, он внушал веру рабочим в свои силы; в известной мере он обуздывал произвол капиталистов» [5, с. 20]. Рабочие уже имели право, но не возможность, обратиться с жалобой в суд на нарушение их условий работы. К сожалению, «...pабочие лишены были возможности отыскивать законными средствами защиту своих прав, ибо невыполнение договоров о найме обеспечивалось общими средствами судебной защиты, которые являлись для рабочих почти недоступными...» [13, с. 47].

Таким образом, «Правила о надзоре за заведениями фабричной промышленности и взаимных отношениях фабрикантов и рабочих» хотя и расширяли права рабочих, но не давали возможности воспользоваться этими правами.

Закон от 1886 г. изначально был распространен только на три губернии: Санкт-Петербургскую, Московскую и Владимировскую. На территории всей остальной России Закон стал действовать только в 1897 г. [5, с. 20]. В этом же году появляется и Закон от 2 июня 1897 г. «О продолжительности и распределении рабочего времени в заведениях фабричнозаводской промышленности» [23, с. 355]. Законом ограничивалось дневное рабочее время. Оно должно было составлять 11,5 часа. Никаких отдельных распоряжений относительно работы женщин на фабриках и заводах этот законодательный акт не предусматривал. Число сверхурочных часов не должно было превышать 120, но циркуляром министра эта норма была отменена в 1900 г. «...Если фабриканту почему-либо необходима сверхурочная работа, то он - под угрозою лишить рабочих места - может всегда заставить их исполнять свое требование» [12, с. 69]. Кроме того, фабриканты злоупотребляли сверхурочными работами [24, л. 14; 25, с. 188-189]. Сам Закон обманывал рабочего, создавая иллюзию того, что он может заработать лишнюю копейку на сверхурочных работах [10].

Уже «...20 сентября 1897 г. министерство финансов по соглашению с министром внутренних дел издало правила, позволяющие по «техническим причинам» в некоторых случаях увеличивать рабочий день до 16 и даже до 18 часов в сутки и допускали повышение средней продолжительности рабочего времени с 11,5 до 12 часов» [14, с. 23]. То есть и здесь Закон больше оставался просто декларацией, чем реально действующим постановлением. Но интересно, что «одна из проблем реформы женского труда, причем не только в России, заключалась в том, что женщины зачастую не желали сокращения рабочего времени или улучшений условий работы, что и после революции будет вызывать озабоченность русского рабочего движения» [26, с. 235]. Это было связано в 
первую очередь с тем, что на большинстве предприятий фабрично-заводской промышленности женщины работали сдельно. Чем большее количество часов они проводили на предприятии, тем выше была их заработная плата. На Резиновой мануфактуре (Товарищество Российско-Американской резиновой мануфактуры - O.C.) в 1898 г. рабочие просили фабричного инспектора сократить время обеда, «чтобы иметь возможность больше заработать» [27].

3 июня 1903 г. были приняты «Правила о вознаграждении потерпевших вследствие несчастных случаев рабочих и служащих, а равно членов их семейств, в предприятиях фабрично-заводской, горной и горнозаводской промышленности» [28]. Они должны были гарантировать всем работникам, пострадавшим от несчастного случая на предприятии, получить вознаграждение, соразмерное полученным увечьям. В случае смерти потерпевшего выплата пособия предназначалась семье погибшего. Удивительно, но «некоторые из членов Государственного Совета опасались, не возникнет ли с введением в действие нового закона «несуществующий в России» рабочий вопрос» $[12$, с. 95]. До принятия этого закона при получении травмы на производстве рабочий пользовался общегражданским законодательством $[29$, с. $81 ; 30]$. Законодатели постарались уменьшить риски хозяев предприятий:

- размер выплат был сделан в пользу работодателей. «При исчислении размера пенсионного обеспечения пострадавшего работника за основу брался его средний годовой заработок, определявшийся путем деления фактического заработка на число фактических рабочих дней и умножения полученного частного на 260. Но число рабочих дней заведомо больше, чем 260 (фактически 300 дней). Следовательно, работодатель всегда оставался в лучшем положении, чем наемный работник» [29, с. $84-85]$;

- закон не действовал на предприятиях, где число работников было менее 20 человек. Но большинство заводов в Российской империи были небольшими предприятиями, с количеством работников не более 20 [29, с. 84];

- вознаграждение не выплачивалось, если рабочий получил травму по своей неосторожности [12, с. 100; 3, с. 79]. А ведь «основной причиной высокого травматизма было полнейшее равнодушие хозяина и мастеров к вопросам техники безопасности» $[4$, c. 39];

- «отсутствие ответственности предприятия при наступлении нетрудоспособности или смерти работника в результате профессионального заболевания» $[29$, с. 84];

- при получении травмы работником хозяин предприятия обязан был оплачивать ему лечение в течение четырех месяцев. Если работник получал инвалидность, то ему выплачивалось пособие, но если человек приступал к работе, а потом опять заболевал, то никаких выплат не следовало делать, чем и пользовались предприниматели. Слегка подлечившегося рабочего они брали на прежнее место с прежним окладом, а затем просто выбрасывали его на улицу.

Только в 1912 г. принимаются социальные законы: «Об обеспечении рабочих на случай болезни», «О страховании рабочих от несчастных случаев»,
«Об учреждении присутствий по делам страхования рабочих» и др. [31]. В результате принятия этих законодательных актов «...в Российской империи впервые была сформирована правовая база, которая по своим основным параметрам вполне была сопоставима с соответствующим европейским законодательством...» [32, с. 222].

На промышленных предприятиях должны были создаваться больничные кассы, в правление которых входили представители администрации и рабочих. Впервые в представители от рабочих могли быть выбраны и мужчины и женщины, что «...способствовало преодолению приниженного положения женщин в российском обществе» [29, с. 78]. Самым важным приобретением с выходом этих законов, в деле получения социальной помощи женщинами-работницами, был оплачиваемый отпуск на две недели до и четыре недели после родов.

Существенными недостатками Закона были:

- вся ответственность ложилась на предпринимателей, которые, естественно, пытались избежать лишних расходов, а они должны были вносить 2/3 суммы в больничную кассу;

- происходило насаждение мелких фабричных касс на отдельных предприятиях. Владельцы имели прямое воздействие на ведение дел в кассе, повышалась опасность невыплат по платежам больничных касс, в случае банкротства предприятия [29, с. 78];

- не требовалось от владельца предприятия создания собственной больницы или амбулатории на заводе или фабрике. «Тем самым в Положении фактически перечеркивались даже минимальные требования к работодателям, определенные Законом 1866 г., по содержанию больниц и амбулаторий при фабриках» [29, с. 79];

- работодатели не несли прямой ответственности за вред, причиненный работнику, даже при наступлении постоянной нетрудоспособности или смерти рабочего от профессионального заболевания;

- отсутствовали специальные медицинские экспертные комиссии, которые определяли бы степень потери трудоспособности работником, этим занимались врачи, которых нанимал работодатель [29, c. 84].

Законы от 1912 г. стали последними в попытке властей улучшить уровень жизни работниц. Так и не были рассмотрены многие ключевые вопросы социальной защиты женщин, тружениц промышленности:

- о равной оплате труда мужчин и женщин;

- о выплатах пенсий по старости, хотя на некоторых предприятиях существовала своя внутренняя система преданным работникам и работницам, отработавшим длительный период на одной фабрике [33, c. $13,44-45 ; 15$, с. $165-166]$;

- об оплачиваемом отпуске;

- не были законодательно закреплены санитарные нормы при постройке и функционировании фабрик и заводов, хотя именно отсутствие гигиенических норм чаще всего приводило к профессиональным заболеваниям [6];

- вопрос о «профессиональных болезнях» также не рассматривался.

Можно было бы еще отметить некоторые недоработки законодателей, но, хотя фабричные законы и 
обладали рядом существенных недостатков, они всетаки в какой-то мере облегчали и экономическое, и правовое положение работниц, что и являлось основной мерой социальной помощи женщин.

Принятие законов является, конечно, первым и основным этапом в системе создания мер социальной защиты, но не единственным. После принятия закона всегда должна следовать стадия формирования контроля над его исполнением и санкций в случае нарушения. Так же, как и на этапе создания законов, власти не смогли полностью и эффективно справиться с поставленной задачей.

С 1 июля 1882 г. начала свою работу фабричная инспекция. «В полномочия фабричных инспекторов в 1882 г. входило лишь только ознакомление с правовым положением рабочих на промышленных предприятиях, доведение норм Закона 1 июня 1882 г. до фабрикантов и сбор статистического материала по данным вопросам» [34, с. 14]. Изначально фабричные инспектора разговаривали с рабочими, выясняли проблемы и пытались решить [7, л. 1-2]. Но затем, дабы не вызывать «наружу таящееся внутри рабочих недовольство», фабричные инспектора «совершенно отказываются от излишних расспросов» $[12$, с. 51]. Появились тайные циркуляры от 8 апреля 1897 г. и от 12 августа 1897 г., в которых предписывалась необходимость разъяснять рабочим, что стачками они ничего не добьются, и никаких уступок им не делать, пока стачка не закончится [12, с. 51-52; 10]. А в Законе от 1 февраля 1899 г. разрешалось устраивать «при фабриках карцеры, куда можно было бы сажать непокорных рабочих» [12, с. 52]. Постепенно, фабричная инспекция из друга и защитника рабочих превратилась в орган полицейского надзора. Иногда сами предприниматели уже готовы были пойти на какие-то уступки рабочим, но инспектора не разрешали им этого делать, «не желая способствовать «развитию в рабочих особой притязательности» $[12$, c. 52].

Санкт-Петербургская губерния в 1900 году была поделена на 13 участков, к каждому из которых был приставлен фабричный инспектор. За каждым инспектором числилось 903 промышленных заведения. Понятно, что за год инспектор мог посетить один или два раза закрепленные за ним фабрику или завод. Кроме того, что инспектора не имели в своих руках веских инструментов для наказания предпринимателей за нарушение законодательства, они и сами подвергались постоянным нападкам со стороны хозяев предприятий. Старший фабричный инспектор Санкт-Петербургской губернии Г. Рыковский в своем донесении в Департамент торговли и мануфактур просил привлечь петербургского фабриканта Джеймса Бека к уголовной ответственности за нарушение фабричного законодательства. Кроме того, инспектор докладывал, что и другие его коллеги, побывавшие на фабриках Товарищества Торнтон, Невской Ниточной, Спасской и Петровской бумагопрядильне, Новой бумагопрядильне, не раз подвергались инсинуациям в адрес и фабричной инспекции, и устава о фабричной и заводской промышленности [35, л. 3]. Инспекторам предлагали взятки, подарки, наконец, их просто избегали. Или забрасывали огромным количеством внутренних актов, которые принимались на предприятии, и фабричный инспек- тор должен был их проверить и подписать. Он просто физически не мог справиться с потоком работы, которую ему необходимо было сделать.

Поднимался и вопрос о создании института фабричных инспектрис, способных лучше разобраться в проблемах именно женского пролетариата. «Необходимость введения женской фабричной инспекции в России была вызвана и ее существованием в ряде стран Европы и Соединенных Штатах Америки» [36, c. 62]. Фабричный инспектор Б.Д. Беликов полагал, что властям необходимо обратить особое внимание на положение женщин-работниц, урегулировать условия их работы и создать учреждения особенно тщательного надзора за их трудом [37, с. 62].

Заведующий отделом промышленности В.П. Литвинов-Фалинский, сам когда-то работавший фабричным инспектором, высказался против введения должности фабричных инспектрис. Аргументом против введения данной должности было то, что «...на чинах фабричной инспекции лежат обязанности технического свойства, требующие технической подготовки, а женщин с техническим образованием нет...» $[38$, c. 13]. «Законопроект о введении должности фабричных инспектрис в России был принят в 1916 г., но так и не был реализован. Хотя наверняка именно женщины-инспектрисы могли бы лучше разобраться в трудностях женской фабричной работы и предложить новые правила относительно улучшения условий их труда» [39, с. 269].

Завершающим этапом в становлении системы социальной защиты работниц должна была стать предоставленная возможность открыто говорить о своих проблемах. И эта задача в имперской России не была выполнена.

Хозяева предприятий подавали заявления в суд в случае нарушения закона рабочими их предприятий и чаще всего выигрывали судебное делопроизводство. Кроме того, промышленники писали ходатайства о принятие или отмене того или иного законодательного акта, которое принималось во внимание законодателями [13, с. 30-45].

Работницы обращались с различными жалобами к фабричным инспекторам, надеясь получить от них помощь, но быстро поняли неэффективность подобных методов [9, л. $13-15 ; 40$, л. $20 ; 41$, л. $1-1$ об.]. Работницы промышленных предприятий вплоть до революционных событий 1917 г. практически являлись «собственностью» хозяина завода или фабрики. И законодатели не смогли выстроить четкую систему социальной помощи женщинам, трудящихся в промышленной сфере. Но самое главное, женщины не смогли получить возможность законным путем отстаивать свои права. Еще в 1895 г. С.Ю. Витте писал: «В нашей промышленности...преобладает патриархальный склад отношений между хозяином и рабочим. Эта патриархальность во многих случаях выражается в заботливости фабрикантов о нуждах рабочих и служащих на его фабрике, в попечениях о сохранении лада и согласия, в простоте и справедливости во взаимных отношениях. Когда в основе таких отношений лежит закон о нравственных и христианских чувствах, тогда не приходится прибегать к применению писаного закона и принуждения» [10].

Подводя итог, хотелось бы отметить, что система целенаправленной государственной социальной защиты и поддержки на промышленных предприятиях 
является залогом политической стабильности в стране. Право и возможность конструктивного диалога между властью, промышленниками и наемной рабочей силой есть прямой путь к решению социальных проблем населения. Законодательные акты, изданные в Российской империи для работников промышленной сферы, должны были существенно улучшить положение женщин, трудящихся на заводах и фабриках. Но, к сожалению, не все из законов выполнялись, а некоторые практически отменялись другими, более поздними постановлениями.

Во второй половине XIX - начале XX в. в СанктПетербурге социальное обеспечение на промышленных предприятиях лежало в плоскости личных взаимоотношений между работницами и хозяевами заводов и фабрик. Работодатели могли по собственному усмотрению принять или уволить работницу. Регулировали ее рабочее и праздничное время, сверхурочные работы и штрафы. Размер заработной платы также устанавливался хозяином предприятия по своему желанию. Власти не смогли найти эффективных методов урегулирования взаимоотношений между работницами и работодателями. Женщины не получили инструментов для борьбы против своего приниженного положения и защиты своих прав.

\section{Список литературы:}

1. Веременко В.А. Современная историография истории повседневности в России // Города Центрального Казахстана в 1950-1960 гг.: История и повседневность. 2017. С. 8-33.

2. Крузе Э.Э. Положение рабочего класса России в 1900-1914 гг. Л.: Наука, 1976. 300 с.

3. Шабалин Б.И. Фабрика на Обводном. Очерк истории завода Красный Треугольник. Книга первая. 1860-1917. Л.: Лениздат, 1949. 340 с.

4. Сукновалов А.Е., Фоменков И.Н. Фабрика «Красное знамя». Очерки истории Ленинградской государственной ордена Ленина трикотажно-чулочной фабрики «Красное знамя». 1855-1967. Л.: Лениздат, 1968. 448 c.

5. Ацаркин А.Н. Жизнь и борьба рабочей молодежи в России (1900 - октябрь 1917). 2-е перераб. и доп. изд. М.: Мысль, 1976. 415 с.

6. Северцева О.В. Болезни, увечья и компенсация при их получении женщинами-работницами фабрик и заводов Санкт-Петербурга во второй половине XIX - начале ХХ вв. // Клио. 2016. № 2. С. 66-69.

7. Центральный государственный исторический архив (ЦГИА СПб.). Ф. 1229. Оп. 1. Д. 44.

8. ЦГИА СПб. Ф. 1229. Оп. 1. Д. 74.

9. ЦГИА СПб. Ф. 1229. Оп. 1. Д. 15.

10. Куприянова Л.В. «Рабочий вопрос» в России во второй половине XIX - начале XX в. [Электронный ресурс] // Исторический факультет МГУ. http://hist.msu.ru/labour/article/kupriyanova.htm.

11. Абрамов Я. Из фабрично-заводского мира. Ч. I // Отечественные записки. 1882. № 3. С. 1-27.

12. Тютрюмова Р.А. Фабричное законодательство в России. М.: Польза. 1908. 359 с.

13. Литвинов-Фалинский В.П. Фабричное законодательство и фабричная инспекция в России. СПб.: Типография А.С. Суворина, 1904. 344 с.

14. Иванов Ю.М., Пронин С.В. На пути свержения царизма. М.: Карпов, 2004. 52 с.
15. Мамчун В.В. Социальное государство России середины - конца XIX в.: риски интерпретаций // Вестник Владимирского юридического института. 2015. № 4. С. 161-167.

16. Лунц М.Г. Из истории фабричного законодательства, фабричной инспекции и рабочего движения в России: сб. ст. М.: Тип. «Печ. дело», 1909. 384 с.

17. Олейникова С.С. Становление нормативноправовой основы социальной защиты трудящихся России XIX - начала XX веков // Философия социальных коммуникаций. 2015. № 1. С. 50-58.

18. Полное собрание законов Российской империи. Собрание третье. 1 марта 1881 года - 1913 год: в 33 т. Т. V. СПб., 1885. № 3013. С. 261.

19. Северцева О.В. Продолжительность и распределение рабочего времени женщин на заводах и фабриках Санкт-Петербургской губернии во второй половине XIX - начале XX в. // Столица и провинции: взаимоотношения центра и регионов в истории России: материалы всерос. науч. конфер. с междунар. участием. Вып. 7. СПб., 2016. С. 48-52.

20. Полное собрание законов Российской империи. Собрание третье. 1 марта 1881 года - 1913 год: в 33 т. T. VI. 1886. № 3769. C. 262-270.

21. Миронов Б.Н. Социальная история России периода империи (XVIII - начало XX в.): генезис личности, демократической семьи, гражданского общества и правового государства. Т. 1-2. СПб.: Дмитрий Буланин, 2003. 548 с.

22. Веременко В.А. Лицо с видом на жительство (гендерный аспект паспортной системы России конца XIX - начала XX вв.) // Адам и Ева: Альманах гендерной истории. М., 2004. № 7. С. 201-242.

23. Полное собрание законов Российской империи. Собрание третье. 1 марта 1881 года - 1913 год: в 33 т. Т. XVII. СПб., 1900. № 14231. С. 355-366.

24. ЦГИА СПб. Ф. 1229. Оп. 1. Д. 39.

25. История рабочих Ленинграда. Том первый. 1703 - февраль 1917. Л.: Наука, 1972. 556 с.

26. Стайтс Р. Женское освободительное движение в России: феминизм, нигилизм и большевизм. 18601930. М.: РОССПЭН, 2004. 614 с.

27. Резиновая мануфактура // Рабочая мысль. 1898. № 3 .

28. Полное собрание законов Российской империи. Собрание третье. 1 марта 1881 года - 1913 год: в 33 т. Т. XXIII: в 2 отделениях. Отделение 1. СПб., 1905. № 23060. С. 595-606.

29. Ермаков Д.Н. Сравнительный анализ развития права социального страхования России и Германии (вторая половина XIX - первая четверть XX вв.) // Государство и право. 2011. № 4. С. 74-87.

30. Попова А.Д. Трудовые споры в судах дореволюционной России как атрибут экономической повседневности // Материальный фактор и предпринимательство в повседневной жизни населения России: история и современность: материалы конф. СанктПетербург, 17-19 марта 2016. СПб., 2016. С. 69-73.

31. Полное собрание законов Российской империи. Собрание третье. 1 марта 1881 года - 1913 год: в 33 т. Т. XXXII: в 2 отделениях. Отделение 1. СПб., 1915. № 37444-37447. С. 847-882.

32. Хаконова И.Б. Особенности проведения страховой кампании по социальному страхованию рабочих в завершающий период Российской империи 
(1913-1916 гг.) // Вестник Адыгейского государственного университета. Серия 1: Регионоведение: философия, история, социология, юриспруденция, политология, культурология. 2013. № 2 (118). С. 222-227.

33. Домбровский О. Быт фабричных рабочих по данным Первой всерос. гигиенической выставки, устроенной Русским Обществом охранения народного здравия в Санкт-Петербурге в 1893 году. СПб.: Типография П.П. Сойкина, 1894. 45 с.

34. Ташбекова И.Ю. Правовое регулирование деятельности фабричной инспекции в России в конце XIX - начале XX вв.: автореф. дис. ... канд. юрид. наук. М., 2006. 27 с.

35. ЦГИА СПб. Ф. 1229. Оп. 1. Д. 48.

36. Гурская В.С. Проблема организации женской фабричной инспекции в России в конце XIX - начале XX вв. // Модернизация в России: история, политика, образование: мат-лы всерос. науч. конф. с междунар. участием, 20 апреля 2015 г. Вып. 7. 2015. С. 44-47.

37. Беликов Б.Д. Женщина в промышленной инспекции запада. К вопросу о введении женской фабричной инспекции в России. Тверь: Типо-Литография М.В. Беликова, 1914. 63 с.

38. Принятие законопроекта о женщинах - фабричных инспекторах // Мир женщины. 1912. № 7-8.

39. Северцева О.В. Охрана труда женщин - фабричных работниц во второй половине XIX - начале XX вв. // Государство и право: эволюция, современное состояние, перспективы развития (навстречу 300-летию российской полиции): материалы науч.теор. конф. СПб., 2016. С. 269-272.

40. ЦГИА СПб. Ф. 1229. Оп. 1. Д. 106.

41. Российская национальная библиотека. Отдел рукописей. Ф. 341. Ед. хр. 661.

\title{
SOCIAL PROTECTION OF FEMALE WORKERS AT SAINT PETERSBURG INDUSTRIAL ENTERPRISES IN THE SECOND HALF OF THE XIX - EARLY XX CENTURY AS ONE OF THE ASPECTS OF EVERYDAY LIFE FEMALE HISTORY
}

(C) 2018

\author{
Severtseva Olga Valentinovna, lecturer of history
}

Vyborg Institute (branch) of Pushkin Leningrad State University (Vyborg, Leningrad Region, Russian Federation)

Abstract. The paper refers to the measures of social protection of female workers at St. Petersburg industrial enterprises in the second half of the XIX - early XX century. Social security is an important part of any person's everyday life, especially women. Laws adopted in the Russian Empire, within the framework of factory legislation, were aimed at supporting the interests of industrial entrepreneurs rather than female workers. Legislative acts that were supposed to guarantee social protection for women workers were practically not observed. Many of these laws were even abolished by later regulatory acts. Female workers did not receive equal wages with men. Women had to work long hours in unsanitary conditions. Female workers were almost «slaves» for the owner of an industrial enterprise. Factory inspectors could not help women workers solve their problems. The authorities did not provide social protection for women in St. Petersburg, who worked for factories in the second half of the XIX - early XX century.

Keywords: everyday life; female workers; industrial enterprises; St. Petersburg; social protection; factory legislation; working hours; salary; fines; overtime work; work-related injuries; leave for pregnancy and childcare; female factory inspection; protection of rights.

УДК 502.04 (252.51) (470.56)

Статья поступила в редакцию 14.06.2018

\section{ОПЫТ ОРГАНИЗАЦИИ СТЕПНЫХ ЗАПОВЕДНИКОВ В ЮЖНОМ ПРЕДУРАЛЬЕ В КОНЦЕ ХІХ - ПЕРВОЙ ТРЕТИ ХХ ВЕКОВ В КОНТЕКСТЕ СОВРЕМЕННЫХ ЗАДАЧ УСТОЙЧИВОГО РАЗВИТИЯ СТЕПЕЙ РОССИИ В ХХІ ВЕКЕ}

(C) 2018

\author{
Мишанина Елена Владимировна, кандидат исторических наук, \\ научный сотрудник отдела степеведения и природопользования \\ Институт степи УрО РАН (г. Оренбург, Российская Федераџия) \\ Мишанина Екатерина Вячеславовна, магистрант кафедры истории России \\ Оренбургский государственный педагогический университет (г. Оренбург, Российская Федерация)
}

Аннотаиия. В статье рассмотрена история двух степных заповедников, существовавших на территории
Ожного Предуралья (современная Оренбургская область). Первый образован А.Н. Карамзиным в частном
владении Полибино Бугурусланского уезда Самарской губернии на рубеже ХІХ-ХХ вв. Площадь его состав-
ляла 650 га, местонахождение, период существования, а также проводимая в нем научная и практическая де-
тельность оставались неизвестными. На его территории исследовались флора, фауна, велись метеорологи-
ческие наблюдения. Полученные данные опубликованы владельцем в ряде монографий. В нач. 1920-х гг. его
площадь поверглась полной распашке. Второй заповедник под названием «Козяка» открыт в Курманаев-
ском районе Средне-Волжского края стараниями директора Пензенского государственного заповедника
И.И. Спрыгина и просуществовал с 1930 по 1935 гг. Он представлял собой значительный массив целинной
степи и долговременных залежей, богатых степным биоразнообразием. Был утрачен при передаче из Средне-
Волжского края в Оренбургскую область. Изучение опыта создания степных заповедных участков имеет науч-
ное и практическое значение при их проектировании и выделении в дальнейшем с целью создания особо охра-
няемых природных территорий, а также определения охранного статуса существовавших ранее заповедников. 